\title{
Persistence of Multiple Maternal Genotypes of Human Immunodeficiency Virus Type I in Infants Infected by Vertical Transmission
}

\author{
Susanna L. Lamers, * John W. Sleasman, ${ }^{\star \star}$ Jin Xiong She, * ${ }^{*}$ Kimberly A. Barrie, * Steven M. Pomeroy, * \\ Douglas J. Barrett, ${ }^{* *}$ and Maureen M. Goodenow**\$ \\ Department of *Pathology, ${ }^{\ddagger}$ Department of Pediatrics, Division of Immunology, and the ${ }^{\S}$ Center for Mammalian Genetics, \\ University of Florida College of Medicine, Gainesville, Florida 32610
}

\begin{abstract}
The extent of nucleotide variation within the HIV-1 env hypervariable domains serves as a marker of virus genotypes within infected individuals and as a means to track transmission of the virus between individuals. We analyzed env V1 and V2 sequences in longitudinal samples from two HIV-1-infected mothers, each with three children infected by maternal transmission of the virus. Sequences in samples that were obtained from two infants at $2 \mathrm{~d}$ and 4 wk after birth displayed more variation in V1 and V2 than maternal samples obtained at the same times. Multiple HIV-1 genotypes were identified in each mother. In each family, multiple maternal HIV-1 genotypes were transmitted to the infants. Specific amino acid residues in the hypervariable domains were conserved within sequences from each family producing a family-specific amino acid signature pattern in V1 and V2. Viruses that were highly related to maternal viruses in signature pattern persisted for as long as 4 yr in the older children. Results support a model of transmission involving multiple HIV-1 genotypes with development of genetic variation from differential outgrowth and accumulation of genetic changes within each individual. (J. Clin. Invest. 1994. 93:380-390.) Key words: human immunodeficiency virus 1 genetic variation - maternal transmission
\end{abstract}

\section{Introduction}

Maternal transmission of human immunodeficiency virus type 1 (HIV-1) occurs in $~ 15$ to $35 \%$ of infants born to infected women $(1-10)$. Why more than two thirds of the infants born to HIV-1-infected women apparently escape infection by the virus raises important questions about virus-host interactions. Mother-to-child transmission of HIV-1 is undoubtedly multifactorial, although the factors that contribute to, or inhibit, maternal transmission of HIV-1 are not completely defined (11). Because passive maternal antibody is the primary immunity that a fetus acquires, it is likely that maternal humoral immunity is one factor in vertical transmission of HIV-1 (1215). However, the specificities of maternal antibodies that can protect against HIV-1 transmission are unclear (16-20). It is also likely that factors related to maternal virus titers, virus

Address correspondence to Dr. Maureen M. Goodenow, Department of Pathology, Box 100275, University of Florida College of Medicine, Gainesville, FL 32610.

Received for publication 21 January 1993 and in revised form 13 July 1993.

J. Clin. Invest.

(C) The American Society for Clinical Investigation, Inc. $0021-9738 / 94 / 01 / 0380 / 11 \quad \$ 2.00$

Volume 93, January 1994, 380-390 tropism for different cell types, and virus variability contribute to vertical transmission.

Genetic variation within HIV-1 in vivo can have a signifcant impact on the biological characteristics and pathogenesis of the virus (21-25). Phenotypic changes of the virus can be related directly to genetic changes that result in a high frequency of amino acid substitutions, deletions, and insertions clustered in five hypervariable domains, V1 to V5, of the envencoded gp 120 molecule $(26,27)$. Multiple functional determinants for virus cell tropism and host immune response map to the env hypervariable domains (28-36).

Nucleotide diversification in HIV-1 env hypervariable domains results in viruses that can be distinguished by genetic analyses (37-41). Analyses of genetic variation primarily in the V3 domain of $e n v$ within infected mother-infant pairs indicated that HIV-1 sequence diversity during the first 4 mo after birth was greater in samples from the mothers than from their infants $(42,43)$. Because there was no evidence in either study for transmission of multiple maternal HIV-1 genotypes to the infants, it was proposed that vertical HIV-1 infection involves selective transmission of a particular maternal variant of the virus.

Our studies have focused on the genetic variability of HIV1 over time in two different families, where neonates and their older siblings were infected by maternal transmission of the virus. The V1 and V2 hypervariable domains of $e n v$ were analyzed because previous studies demonstrated that extensive genetic variability in V1 and V2 could be used to distinguish among strains of HIV-1 (37). The goals were to determine whether or not multiple HIV-1 genotypes were present in the mothers, to assess the possibility that multiple genotypes could be transmitted, and to evaluate the extent of genetic divergence over time in epidemiologically related viruses infecting different individuals.

\section{Methods}

$H I V-1$ infected mothers and children. Samples of peripheral blood were collected over a period of almost $2 \mathrm{yr}$ from members of two families, Family A and Family B (Fig. 1). The mothers, MA and MB, each had three infected children. $A 1$ and $B 1$ indicate the eldest child in each family; A2 and B2, the second child; A3 and B3, the youngest child. Samples are coded with numbers to represent the dates collected. In all cases, the earliest available samples were studied. In several instances, samples were collected from the mothers near the time of conception (Fig. 1). Samples were obtained through the Pediatric Immunology Clinic with maternal informed consent under a protocol approved by the Institutional Review Board of the University of Florida College of Medicine.

Peripheral blood T-cell subsets were analyzed by two-color flow cytometry (FACSCAN ${ }^{\oplus}$; Becton Dickinson \& Co., Mountain View, CA). Sera HIV-1 p24 antigen was determined by antigen capture (Abbott Laboratories, North Chicago, IL). Assays were carried out in the 
Clinical Immunology Laboratory of Shands Hospital at the University of Florida.

MA was identified as HIV-1 infected when A1, her 21-mo-old child, was found to have lymphoid interstitial pneumonitis, lymphadenopathy, and positive HIV-1 serology. MA had no history of intravenous drug use by toxicology profile or evidence of other sexually transmitted diseases. Her risk factor was sexual contact with an intravenous drug user. MA's CD4 T-cell count fell from 587 cells $/ \mathrm{mm}^{3}$ in October 1989 , when she was enrolled in the study, to 38 cells $/ \mathrm{mm}^{3}$ in January 1991, when zidovudine therapy was initiated. MA developed toxoplasmosis as her AIDS-defining illness in June 1991.

The mother in Family B was identified as infected by HIV-1 when her oldest child, B1, was evaluated at 9 mo of age for lymphadenopathy and interstitial pneumonitis. Similar to mother A, MB's risk factor was a sexual partner who was an intravenous drug abuser. MB was asymptomatic with $781 \mathrm{CD} 4$ cells $/ \mathrm{mm}^{3}$ in January 1988 . Her CD4 T-cell count dropped to 296 cells $/ \mathrm{mm}^{3}$ in December 1990 and to 39 cells/ $\mathrm{mm}^{3}$ in October 1991. During that time she developed HIV-associated wasting syndrome but had no opportunistic infections. Antiviral therapy was initiated after October 1991 .

Each of the six children were full-term infants born by spontaneous vaginal delivery with normal birth histories and neonatal physical examinations. There was no clinical evidence for fetomaternal hemorrhage. Clinical profiles of the children are summarized in Table I. Two infants in Family A were breast fed; A1, until 11 mo of age, and A2 until $7 \mathrm{wk}$ of age. Child $\mathrm{A} 1$ developed generalized lymphadenopathy at 14 mo and interstitial pneumonitis at 21 mo. Infant A2 developed pneumococcal meningitis at $18 \mathrm{wk}$ of age. Infant A3 was evaluated at 9 wk of age for fever of unknown origin, oral candidiasis, and lymphadenopathy, and developed Pneumocystis carinii and cytomegalovirus pneumonia at $14 \mathrm{wk}$ of age. Infant B2 was positive for p24 antigen at 3 mo, but clinically asymptomatic until February 1991, when he developed Pneumocystis carinii pneumonia. Infant B3 showed evidence of oral candidiasis and lymphadenopathy at $4 \mathrm{wk}$ of age.

Nucleic acid extraction, amplification, and sequencing. Separation of peripheral blood mononuclear cells (PBMC), DNA purification, and amplification procedures were carried out in a laboratory free of cultured HIV-1 isolates or cloned HIV-1 sequences. DNA was pre- pared from Ficoll-Hypaque separated PBMC according to standard procedures $(45)$.

Sequences of HIV-1 env V1-V2-C2 region were amplified using the PCR and nested oligonucleotide primers prepared in the DNA synthesis core facility of the Interdisciplinary Center for Biotechnology Research at the University of Florida. The outer primers were ENV5 (5'-GGTAGAACAGATGCATGAGGAT-3') and ENV6 (5'-CCATGTGTACATTGTACTGTGCT- $3^{\prime}$ ), located at nucleotides 6102 6123 and $6544-6566$ in the genome of $\operatorname{HIV}_{\text {LAI }}(27)$. The inner primers were SK122 and SK123 (37). HIV-1 env sequences were amplified from $1 \mu \mathrm{g}$ of PBMC DNA in $100 \mu \mathrm{l}$ reactions with PCR buffer ( 1.75 $\mathrm{mM} \mathrm{MgCl}, 50 \mathrm{mM} \mathrm{KCl}, 20 \mathrm{mM}$ Tris- $\mathrm{HCl}, \mathrm{pH} \mathrm{8.4,0.1 \%} \mathrm{BSA} \mathrm{),} 100$ pmol of each outer primer, $200 \mu \mathrm{mol}$ of each dNTP, and 2.5 units Amplitaq (Perkin Elmer Cetus Corp., Norwalk, CT) overlayed with 25 $\mu 1$ mineral oil. Reagent controls and DNA from uninfected cells were included in every experiment. Amplification reactions were carried out in an automated, 48-well thermal cycler (Perkin Elmer Cetus Corp.) programmed for one cycle of denaturation $\left(94^{\circ} \mathrm{C}\right.$ for $\left.10 \mathrm{~min}\right), 25 \mathrm{cy}-$ cles of amplification (each cycle included $1 \mathrm{~min}$ at $94^{\circ} \mathrm{C}, 1 \mathrm{~min}$ at $50^{\circ} \mathrm{C}$, and $2 \mathrm{~min}$ at $72^{\circ} \mathrm{C}$ ), followed by one cycle at $72^{\circ} \mathrm{C}$ for $10 \mathrm{~min}$. After passage through a Centricon 100 filter (Amicon/W. R. Grace \& Co., Beverly, MA) one tenth of the product was used as template in a second round of amplification for 20 cycles with inner primers and the same profile as above.

Amplified products of approximately 400 to 450 basepairs (bp) were isolated from agarose gels and blunt-end ligated into pGEM-3Z plasmid vectors (Promega Corp., Madison, WI). Multiple recombinant plasmids from each sample were sequenced by the dideoxy chain termination method with SP6 and T7 primers, ${ }^{35}$ S-labeled dATP, and Sequenase Version 2.0 (United States Biochemical Corp., Cleveland, $\mathrm{OH}$ ).

Analyses of nucleotide sequences. Sequences were aligned to give minimum evolutionary distances using the multiple aligned sequence editor program (kindly provided by D. Faulkner and Y. Jerka, Molecular Biology Computer Research Resource, Harvard University, Cambridge, MA). After translation of nucleotide sequences using Microgenie (IntelliGenetics, Inc., Mountain View, CA), alignments were subsequently edited by hand due to extensive length variation in the hypervariable domains. The amplified region included 70 to $100 \mathrm{bp}$ of

Table I. Clinical Profiles of HIV-1-Infected Siblings in Two Families

\begin{tabular}{|c|c|c|c|c|c|c|c|c|}
\hline Patient & $\begin{array}{l}\text { Date of } \\
\text { birth }\end{array}$ & $\begin{array}{c}\text { Birth } \\
\text { weight }\end{array}$ & $\begin{array}{l}\text { Sample } \\
\text { code* }^{*}\end{array}$ & Age & CDC stage ${ }^{\ddagger}$ & $\begin{array}{l}\text { CD4 } \\
\text { count }\end{array}$ & $\begin{array}{c}\mathrm{CD} 4 / \mathrm{CD} 8 \\
\text { ratio }\end{array}$ & $\begin{array}{c}\text { HIV } \\
\text { p24 } \mathrm{Ag}^{5}\end{array}$ \\
\hline & & $\mathrm{kg}$ & $m m / w$ & & & cells/s/mm & & \\
\hline \multirow[t]{3}{*}{$\mathrm{A} 3$} & $9 / 16 / 90$ & 2.86 & 0990 & $2 d$ & P1-A & ND & ND & + \\
\hline & & & 1190 & $9 w k$ & P2-A & 1170 & 0.9 & + \\
\hline & & & 0191 & $14 \mathrm{wk}$ & P2-A, B, D1 & 1154 & 0.4 & + \\
\hline \multirow[t]{2}{*}{$\mathrm{A} 2$} & $8 / 30 / 89$ & 2.75 & 1089 & 7 wk & P1-B & ND & ND & + \\
\hline & & & 0190 & $18 \mathrm{wk}$ & P2-A, D2 & 1402 & 2.4 & + \\
\hline \multirow[t]{3}{*}{$\mathrm{Al}$} & $1 / 05 / 88$ & 3.43 & 1089 & $21 \mathrm{mo}$ & P2-A, C & 1342 & 0.3 & - \\
\hline & & & 0590 & $29 \mathrm{mo}$ & P2-A, C & 925 & 0.5 & ND \\
\hline & & & $0191^{\prime \prime}$ & $36 \mathrm{mo}$ & P2-A, C & 1012 & 0.8 & - \\
\hline B3 & $9 / 03 / 91$ & 3.23 & 1091 & $4 \mathrm{wk}$ & P2-A & 2450 & 2.7 & - \\
\hline \multirow[t]{2}{*}{ B2 } & $2 / 04 / 90$ & 3.54 & 0291 & $12 \mathrm{mo}$ & P2-A, D1 & 257 & 0.9 & + \\
\hline & & & 0491 & $14 \mathrm{mo}$ & P2-A, D1 & 1210 & 1.1 & + \\
\hline \multirow[t]{4}{*}{ B1 } & $2 / 21 / 87$ & 3.10 & 0789 & $29 \mathrm{mo}$ & P2-A, C & 200 & 0.2 & + \\
\hline & & & 0989 & $31 \mathrm{mo}$ & P2-A, C & 224 & 0.2 & ND \\
\hline & & & 0890 & $42 \mathrm{mo}$ & P2-A, C & 287 & 0.3 & - \\
\hline & & & $1290^{\prime \prime}$ & $45 \mathrm{mo}$ & P2-A, C & 724 & 0.4 & - \\
\hline
\end{tabular}

* Sample code represents date (month and year) of sample collection and is the same as indicated in Fig. 1 . In all cases the earliest sample indicated was the earliest one obtained. ${ }^{\ddagger}$ Centers for Disease Control classification system for staging of pediatric HIV-1 infection (44). ${ }^{\S}$ Determined by antigen capture test (Abbott Laboratories, North Chicago, IL). "Zidovudine therapy was initiated before these samples. 
$\mathrm{V} 1$ sequences, 100 to $150 \mathrm{bp}$ of $\mathrm{V} 2$, and $140 \mathrm{bp}$ of conserved region $\mathrm{C} 2$. The V1 and V2 domains were defined by the cysteine residues proposed to form disulfide linkages in the region (46).

The program SYNO (kindly provided by M. Nei, Pennsylvania State University, University Park, PA) was used to calculate nucleotide distances transformed by the Jukes-Cantor formula $(47,48)$. The Student's $t$ test was used to evaluate the significance of differences in nucleotide distances within an individual and between individuals (47). Phylogenetic trees resulted from analyses of selected sequences using Fitch-Margolish version 3.2.

Nucleotide sequence accession numbers. Sequences have been submitted to the GenBank database (accession numbers L15085 to L15187), and alignments of sequences have been provided to the $\mathrm{Hu}$ man Retroviruses and AIDS Database. Both data resources are maintained at Los Alamos National Laboratory, Los Alamos, NM.

\section{Results}

$H I V-1$ genetic variation within mothers and their infants. The extent of nucleic acid variation in env V1-V2-C region was analyzed within samples from each of the two mothers and three of their infants, A2, A3, and B3, shortly after birth (Fig. 1). In infant $\mathrm{A} 2$, env sequences were essentially homogeneous in sample A2.1089 obtained at 7 wk of age and in a second sample set, A2.0190, obtained at $18 \mathrm{wk}$ of age (Table II). Yet, variation within maternal sample MA.1089, obtained at the same time as infant sample A2.1089, was $8.2 \%$ across the V1V2-C region, reflecting variation of $22.4 \%$ in $\mathrm{V} 1$ and almost $12 \%$ in V2. It is unlikely that the sequence homogeneity in the infant was due to nonreplicating virus because $A 2$ was positive for p24 antigen at both time points ( see Table I).

In contrast, samples from two infants, A3 and B3, displayed greater nucleotide sequence variation than samples obtained from their mothers at the same time (Table II). Variation in sequences from infant $\mathrm{A} 3$ at $2 \mathrm{~d}$ of age (A3.0990) was $1.3 \%$ compared with variation of $0.2 \%$ in maternal sample MA.0990. Infant samples A3.1190 and A3.0191 increased in variation at 9 and $14 \mathrm{wk}$ after birth, relative to variation in

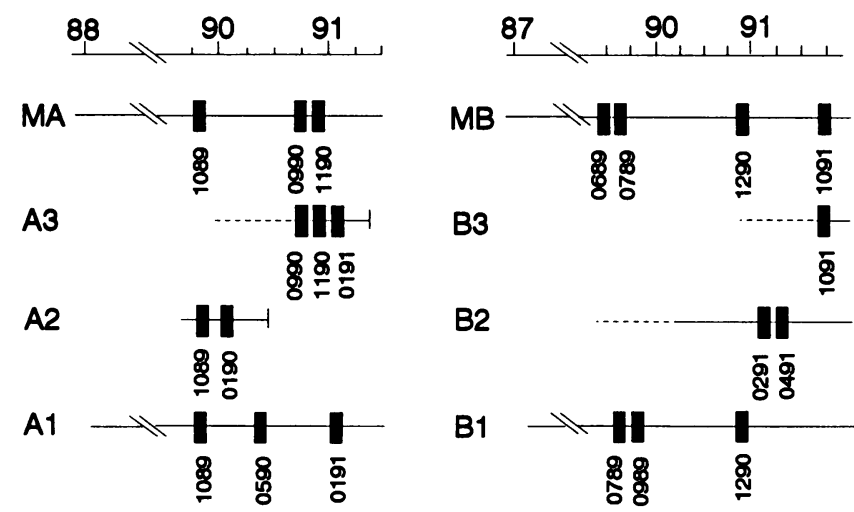

Figure 1. Samples from two families. Family A is on the left; Family B is on the right. Line along the top indicates time in years. Lines beneath date line represent individuals. $\mathrm{MA}$ and $\mathrm{MB}$, mothers; $\mathrm{Al}$ and B1, oldest child; A2 and B2, second child; A3 and B3, youngest child. For infant A2, the horizontal line begins at the time of birth. For infants A3, B2, and B3, dotted lines indicate gestation. Vertical lines designate the death of infants $A 2$ and $A 3$. Black boxes represent samples. Numbers underneath each box designate the sample by the month and year of its collection. Samples with the same number were collected at the same time.
Table II. Nucleic Acid Variation in HIV-1 env within Samples from Mothers and Infants near Birth

\begin{tabular}{|c|c|c|c|}
\hline \multirow{2}{*}{$\begin{array}{c}\text { Sample } \\
\text { set* }\end{array}$} & \multicolumn{3}{|c|}{ Regions of HIV-1 env } \\
\hline & $\mathrm{V} 1 / \mathrm{V} 2 / \mathrm{C}$ & v1 & v2 \\
\hline MA.1089 & $8.2(1.1)^{\dagger}$ & $22.4(3.7)$ & $11.9(2.2)$ \\
\hline A2.1089 & 0 & 0 & 0 \\
\hline A2.0190 & 0 & 0 & 0 \\
\hline MA.0990 & $0.2(0.1)$ & $<0.2(0.2)$ & $<0.1(0.6)$ \\
\hline A3.0990 & $1.3(0.3)$ & $1.0(0.6)$ & $1.5(0.6)$ \\
\hline MA.1190 & $1.6(.02)$ & $2.3(1.1)$ & $2.7(0.9)$ \\
\hline A3.1190 & $3.28(0.4)$ & $1.3(0.5)$ & Ox) \\
\hline A3.0191 & $94(1.1)$ & $11.8(2.3)$ & $92(1.7)$ \\
\hline MB.1091 & $4.5(0.7)$ & $6.3(1.7)$ & $6.8(1.7)$ \\
\hline B3.1091 & fo: $(1.1)$ & $1986(3.5)$ & $10.5(2.3)$ \\
\hline
\end{tabular}

*Each sample set contains five to eight sequences. ${ }^{\dagger}$ Percent mean variation $( \pm \mathrm{SEM}) .{ }^{8}$ Shaded values indicate infant samples that are significantly more variable than maternal samples by Student's $t$ test (53).

maternal env sequences $(P<0.01)$. In general, both the $\mathrm{V} 1$ and V2 domains in sequences from infant A3 were significantly more variable than maternal MA.1190 sequences $(P<0.001)$ (Table II). Likewise in Family B, the population of env sequences from infant sample B3.1091 was more variable across the entire V1-V2-C region than maternal env sequences MB.1091 $(P<0.01)$. These maternal-infant samples were obtained at the same time when B3 was 4 wk of age. Each hypervariable domain varied independently. V1 sequences were significantly more variable in infant sample B3.1091 than in maternal sample MB.1091 $(P<0.001)$, whereas V2 sequences were not $(P=0.1)$. Results of these analyses indicated that HIV-1 sequences in neonates can be significantly more variable than maternal virus sequences at the same point in time.

Genetic variation in V1 and V2 sequences in epidemiologically unrelated viruses. The extent of variation within virus populations that were epidemiologically related in a mother and her infants led us to define the distance between epidemiologically unlinked virus populations. All V1 and V2 amino acid sequences from the two mothers were aligned, guided by the 8 cysteine residues dispersed across the region, and the 12 conserved amino acid residues between V1 and V2 (Table III). Because of length variation in each of the hypervariable domains, spacing was introduced to maximize alignments between the two sets of sequences.

In contrast to the $\mathrm{C} 2$ region, where nucleotide variability between MB and MA sequences was $9.4 \pm 2.5 \%$, distance in the V1 hypervariable domain was $30.5 \pm 4.2 \%$ and in V2, $15.9 \pm 2.7 \%$ ( Table III). Variability in the HIV-1 sequences between the two mothers was not significantly different in some cases from the variation in HIV-1 sequences between infected members of the same family (data not shown). Yet, there was no evidence from the clinical histories of the mothers to indicate that their viruses were epidemiologically linked. The results raised the possibility that genetic variation, which evolved in V1 and V2 over a period of several years, may be too extensive to distinguish between populations of epidemiologically related and unrelated viruses. Alternatively, there can be fea- 


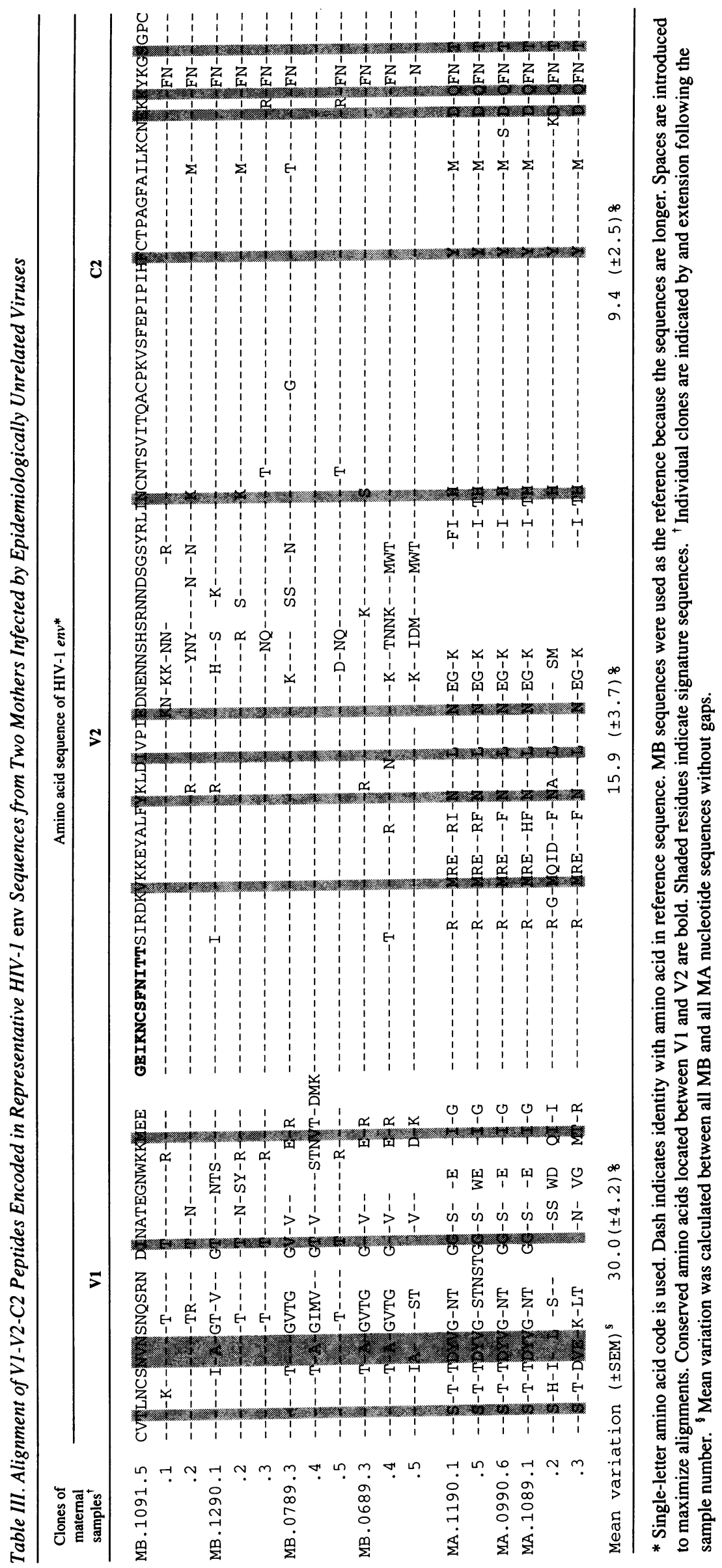


tures of the env sequence, in addition to nucleotide variation, that characterize epidemiologically related viruses. For example, conserved amino acid signature patterns in env contributed to establishing the epidemiological link among HIV-1 variants in a group of infected individuals (41).

Amino acid signature pattern. Based on the alignment of maternal sequences, it was possible to identify a pattern in the V1-V2-C2 region where particular amino acids appeared in nearly all sequences from one mother but not in the sequences from the second mother. This array of amino acids comprises the signature pattern for an individual's sequences. A unique signature pattern was identified in 16 amino-acid positions dispersed along the V1-V2-C region (Table III, shaded positions). Only 4 signature positions were located in the conserved region $\mathrm{C} 2$, whereas 12 signature residues were located in the hypervariable domains, 7 in $\mathrm{V} 1$ and 5 in V2. The pattern of amino acids in these positions did not predominate when V1-V2-C2 sequences from molecular clones of HIV-1 (27) or in HIV-1 isolates (37) were analyzed (data not shown), suggesting that these residues were conserved among epidemiologically related viruses. If this were the case, then V1-V2-C2 sequences within the infants and children in each family should contain their respective maternal signature patterns.

To examine this possibility, representative sequences from each mother were used as reference for the alignment of all sequences from her children. Significantly, the amino acid signature pattern identified in the maternal sequences was present in most sequences from all members of each family (Tables IV and $\mathrm{V}$, shaded residues). The amino acid signature positions in the V1 domain were designated 1 through 7 and those in V2, 8 through 12. Positions in C2, designated 13 through 16 , were also conserved in a family-specific pattern (data not shown).

Analyses of 65 clones from Family A and 57 clones from Family B revealed in general two predominant amino acids at any signature position (Table VI). There was essentially no overlap in amino acid usage at any signature position between sequences from the two families. The family-specific amino acid signature pattern was apparent within epidemiologically related viruses in the face of considerable overall sequence variation. Moreover, the signature patterns persisted for as long as 3 to 4 yr not only in maternal HIV-1 sequences, but in HIV-1 sequences of their children as well.

Transmission of multiple genotypes. It became clear from the alignment of $\mathrm{V} 1$ and $\mathrm{V} 2$ sequences that a number of distinct HIV-1 genotypes could be identified within each mother. Likewise, more than one genotype appeared in most of the children. The relationship between representative maternal virus genotypes and sequences found in the infants or their older siblings was assessed by phylogenetic tree analyses.

In Family A, three major V1 genotypes were found in the maternal sequences, represented by MA.1089.1, MA.1089.2, and MA.1089.3 (Fig. $2 A$, upper diagram). Sequences closely related to two maternal genotypes were found in infant A3. Variant A3.0191.3 clustered with maternal genotype MA.1089.2, whereas several additional A3 variants clustered with maternal genotype MA.1089.1. In the V2 domain, two

Table IV. HIV-1 Amino Acid Signature Sequences in Mother-Child Samples of Family A

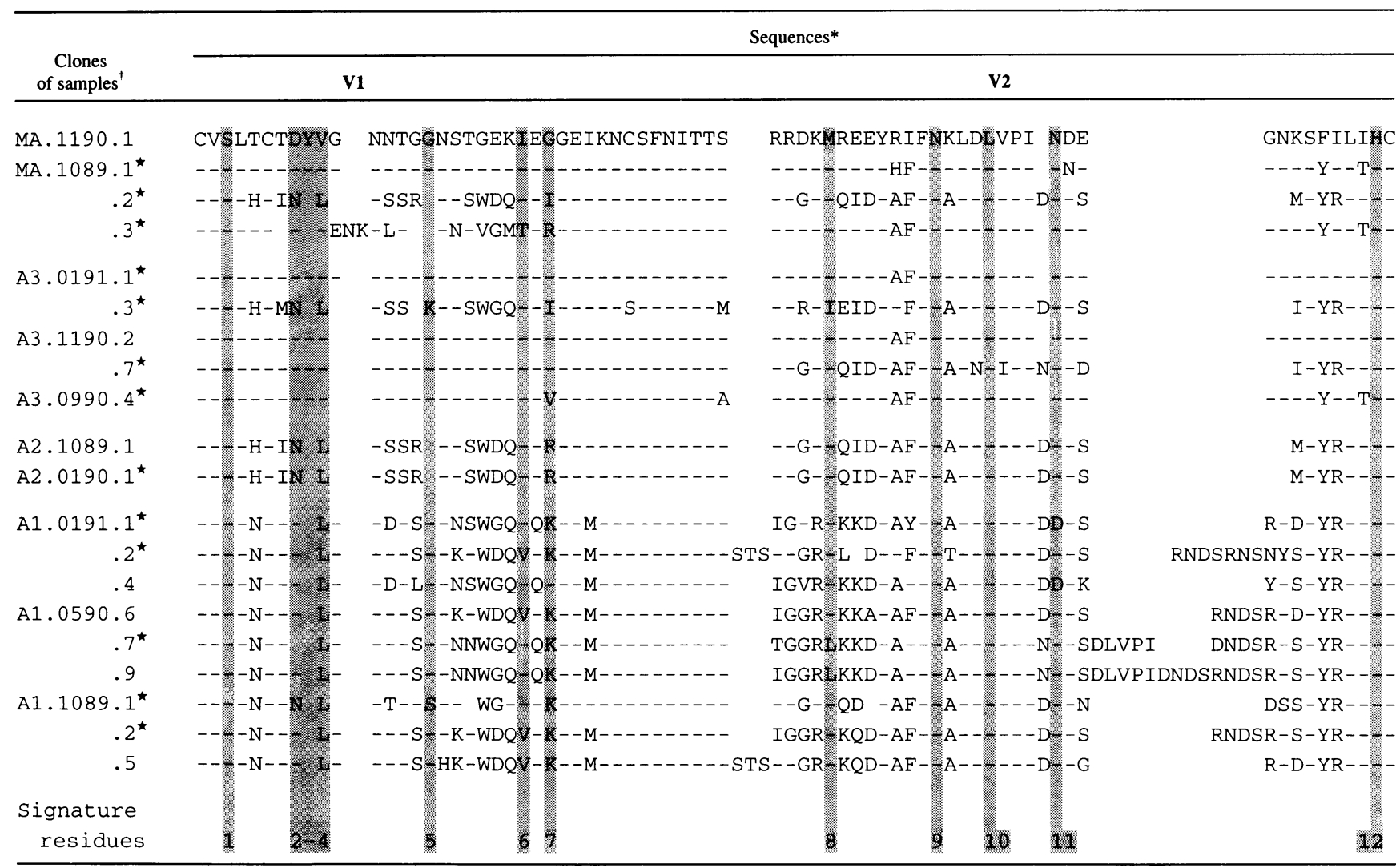

* Alignment of constant region is not included because sequences in children are highly related to maternal sequences. ${ }^{\dagger}$ Sequences of representative clones from a sample are included. Stars indicate sequences included in the phylogenetic tree analyses in Fig. 2. 
Table V. HIV-1 Amino Acid Signature Sequences in Mother-Child Samples of Family B

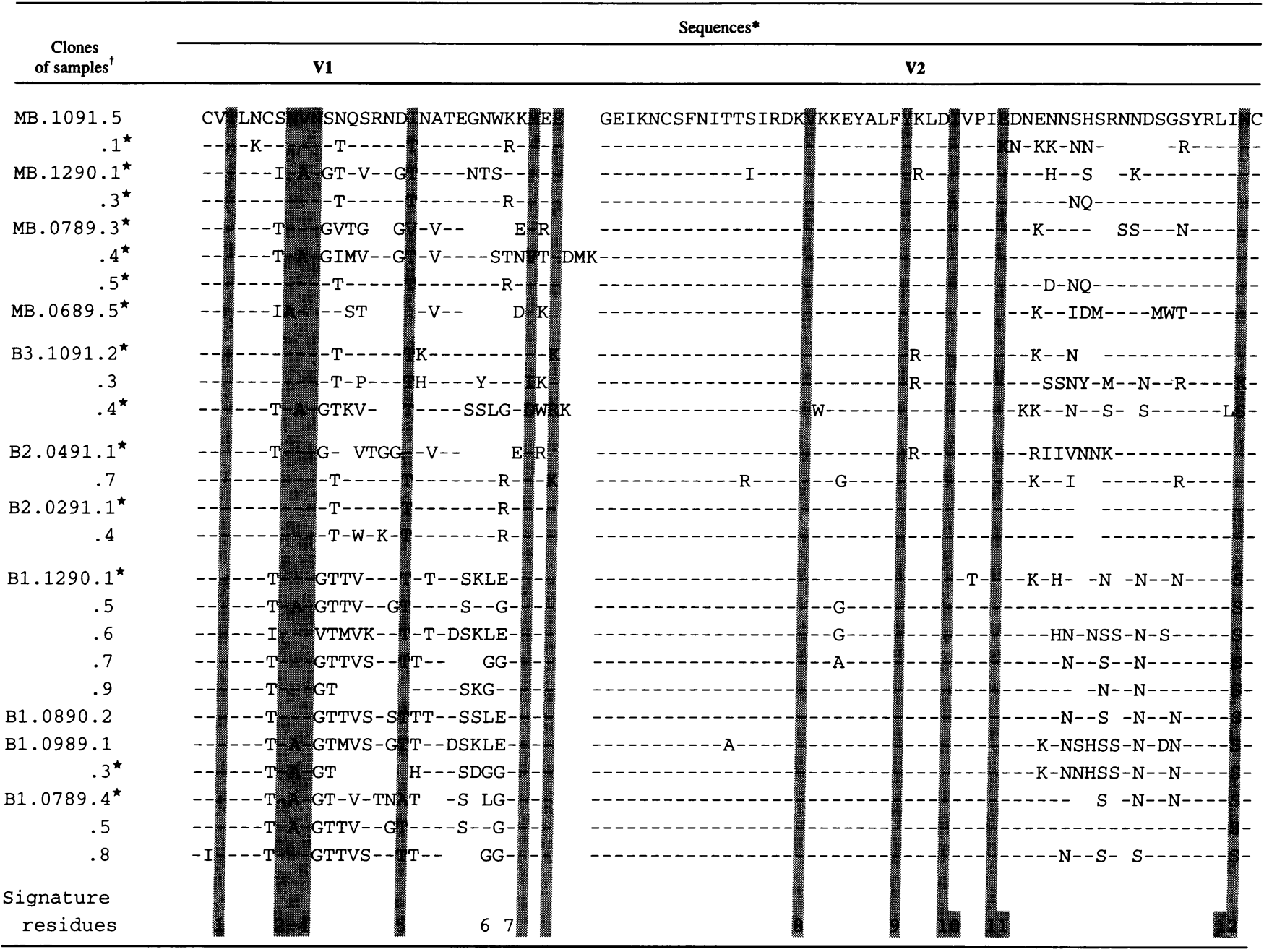

* Alignment of constant region is not included because sequences in children are highly related to maternal sequences. ${ }^{\dagger}$ Sequences of representative clones from a sample are included. Stars indicate sequences included in the phylogenetic tree analyses in Fig. 2.

major genotypes were identified in both the mother and her infant A3 (Fig. $2 A$, lower diagram). Infant sequences A3.0990.4 and A3.0191.1 clustered closely with one maternal genotype, represented by MA.1089.3 or MA.1089.1. A second maternal variant, MA.1089.2, was related to infant sequences A3.1190.7 and A3.0191.3.

Multiple HIV-1 genotypes, particularly in V1, were also found in the mother in Family B (Fig. 2 B, upper diagram). Sequences related to at least two maternal genotypes were identified in infant B3. One infant genotype, B3.1091.2, was closely related to a cluster of maternal variants MB.0789.5, MB.1290.3, and MB.1091.1. Another infant genotype, B3.1091.4, was more related to maternal variant MB.1290.1. There was evidence for multiple maternal HIV-1 genotypes in the second infant, B2, as well. One variant, B2.0291.1, was highly related to the cluster that included maternal and B3 sequences, while a second variant, B2.0491.1, was closely related to maternal variant MB.0789.3.

Persistence of genotypes. Although multiple HIV-1 variants could be transmitted, all variants were not necessarily apparent in either maternal or infant samples near the time of birth. For example, infant variant A3.0191.3 was first identi- fied in a sample obtained when A3 was 14 wk of age (Table I). The maternal progenitor sequence, MA.1089.2, was not found in the mother's samples obtained $2 \mathrm{~d}$ (MA.0990) or $9 \mathrm{wk}$ (MA.1190) after the birth of A3, but did appear in maternal sample MA.1089 obtained $\sim 2$ mo before conception of A3 (Fig. 1).

Many of the individual V1 sequences found in the eldest child Al at 21 to 36 mo of age clustered together and, as a group, were more related to MA.1089.2 than to other maternal variants (Fig. $2 A$, upper diagram). One variant, A1.1089.1, was distinct both from Al sequences in the cluster and from other MA variants. This $\mathrm{A} 1$ variant may represent a virus that evolved independently in the child during the time after transmission. Alternatively, variant A1.1089.1 may reflect yet another maternal variant that was transmitted and persisted in the child.

Persistence of HIV-1 genotypes could be detected in Family B, as well. Although there was a striking similarity in V2 sequences among all members of family $B$, independent of the time that had elapsed between vertical transmission and subsequent samples, V1 sequences were clearly more variable (Fig. 2 $B$, upper and lower diagrams). V1 sequences in samples from 
MB (MB.1091.1) and her infant B3 (B3.1091.2) were closely related to each other and to maternal variant MB.1290.3. The mother-infant samples designated 1091 were obtained 4 wk after the birth of B3, whereas maternal sample MB.1290 was obtained 10 mo earlier, during the first trimester of her pregnancy with B3 (Fig. 1). Even though MB's second infant, B2, was $1 \mathrm{yr}$ of age when samples were first obtained, it was possible to distinguish two variants in B2 (B2.0291.1 and B2.0491.1) that clustered with maternal variants $\mathrm{MB} .0789 .5$ and MB.1290.3, or MB.0789.3, respectively (Fig. 2 B, upper diagram). These maternal variants were identified in samples obtained $\sim 18$ mo apart. One sample was obtained early in July 1989, during the first trimester of her pregnancy with B2 and the second, in December 1990, when B2 was 10 mo of age (Fig. 1). Similarly in MB's oldest child, one variant, B1.1290.1, was closely related to maternal variant MB.1290.1 (Fig. 2 B, upper diagram). These maternal-child samples were collected in December of 1990, when B1 was almost 4 yr of age (Fig. 1).

\section{Discussion}

The extent of nucleotide variation in env defined multiple HIV-1 genotypes in each of the mothers in our studies. A number of distinct maternal HIV-1 genotypes were detectable in the infants in each family. The most plausible explanation for the presence of multiple HIV-1 genotypes in infants is that multiple viruses can be transmitted from the mother. Our results, which indicate that pediatric HIV-1 infection does not always result from selective transmission of maternal HIV-1 variants, differ from other studies in which infants infected by vertical transmission were found to harbor homogeneous virus populations relative to maternal viruses $(42,43)$.

The families in our study were chosen because both mothers had transmitted HIV-1 to multiple infants. Vertical transmission to more than one infant is not unique among HIV-1 infected women with more than one child $(1,3,6,49$, 50 ). The women in our study did not take zidovudine or other antiviral therapies, which might impact the frequency of vertical transmission. Two of the six children whom we studied were breast fed, but there was no evidence that they differed from the other HIV-1 infected children who were not. There were no apparent differences between other studies of vertical transmission and ours with regard to the ages of the infants, which ranged from birth to $\sim 4 \mathrm{mo}$, their deliveries, or their clinical presentation $(42,43)$.

Because our studies were longitudinal, one explanation for our results could be that divergent HIV-1 genotypes evolved independently in infants and their mothers from a common progenitor sequence. Convergent evolution, in which the same amino acid was fixed independently at the same position in the V3 hypervariable domain in more than one HIV-1 variant, apparently developed in vivo over a period of years (51). However, there is no evidence that distinct HIV-1 genotypes, such as those identified in the mothers and infants in our study, can evolve independently within different individuals in a period of weeks. Moreover, different HIV-1 genotypes, which were identified in three of the infants in our studies, were detected before their births in earlier maternal samples.

The most likely explanations for the difference between our results and those from other studies of vertical transmission are that different subgenomic regions of HIV-1 env were analyzed

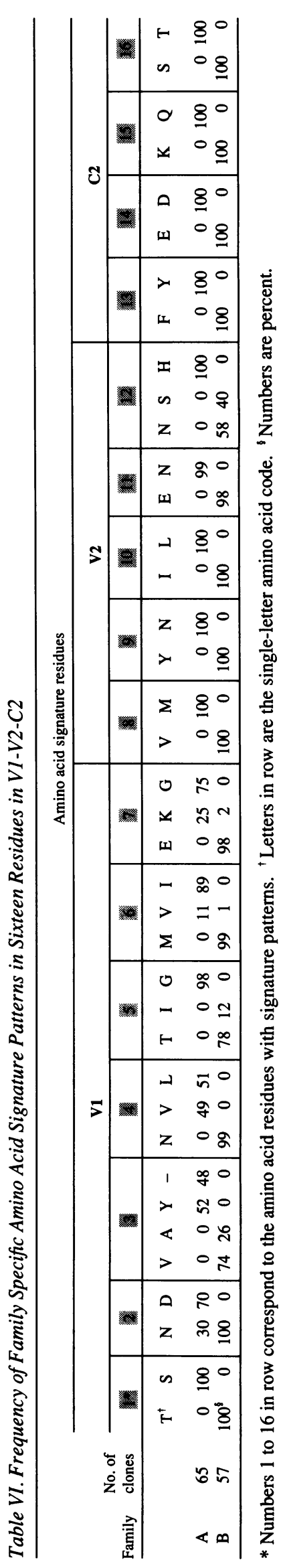




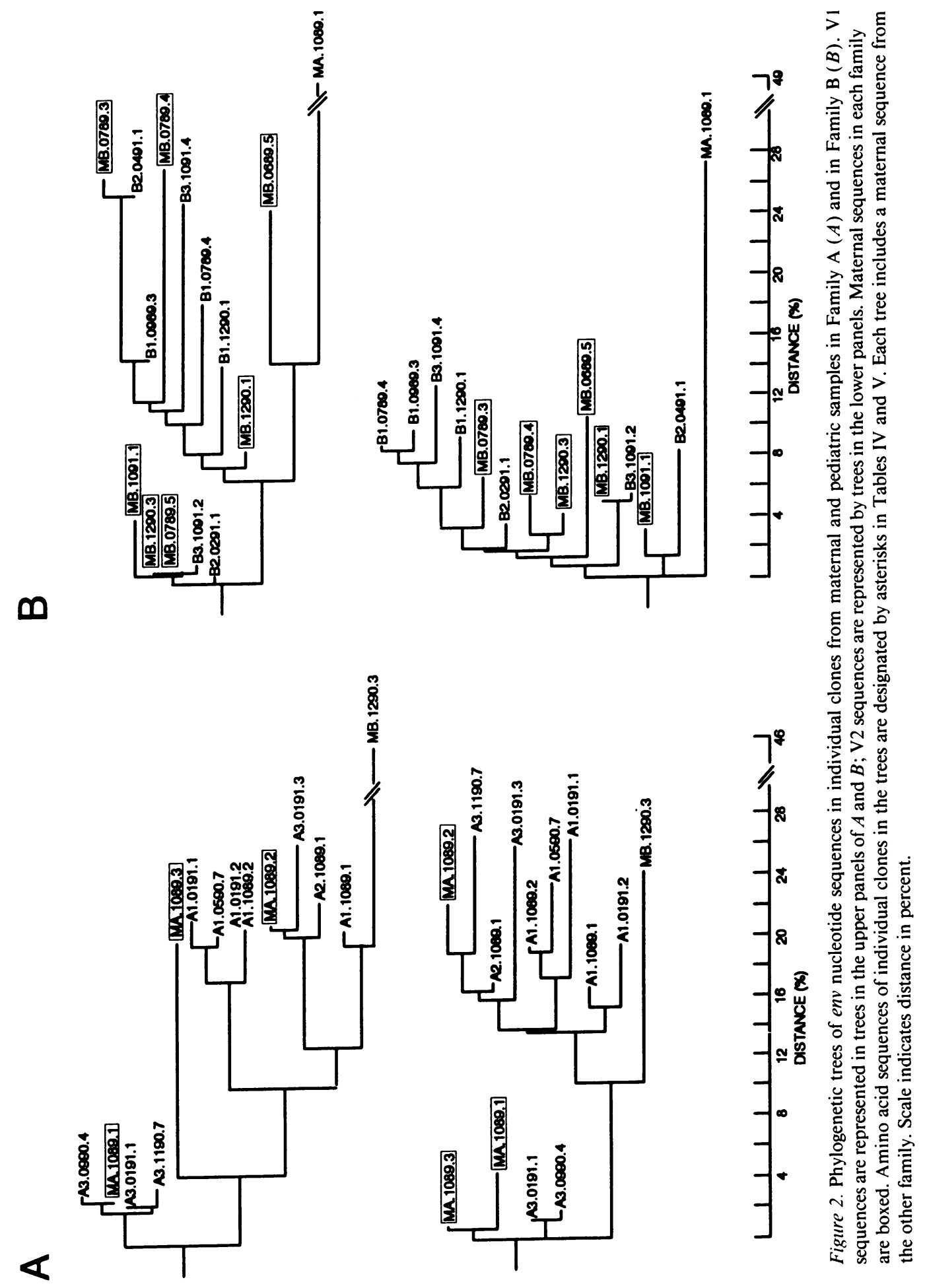


and that our studies were longitudinal. The V3 domain was a focus in other studies of maternal transmission of HIV-1 (42, 43 ). In contrast, both the V1 and V2 hypervariable domains of $e n v$ were assessed in our studies. V1 and V2 vary independently in HIV-1 genomes in vivo and can display more genetic variability than the V3 domain (27, 52-55). Indeed, development of quasispecies of HIV-1 in vivo involved more genetic variability in a region $3^{\prime}$ of the $\mathrm{V} 3$ loop, than in V3 itself (56). Because our studies analyzed virus sequences over time, rather than a single time point, the likelihood of identifying multiple HIV-1 variants within individuals was increased. Different conclusions could have been drawn if we had limited our studies to a single timepoint or to a single region of the HIV-1 genome; for example, the V2 domain, which was relatively homogeneous among all individuals in Family B.

Populations of HIV-1 variants were found to be more heterogenous in samples from two infants during the first few months after birth than in samples from their mothers at the same time. Increased sequence heterogeneity could reflect elevated levels of viremia in neonates early after infection by vertical transmission, similar to early viremia detected in adults after infection by other mechanisms (57-59). One infant in our study displayed homogeneous sequences in V1 and V2 at two separate time points, suggesting selective transmission of one maternal HIV-1 variant. Yet, restricted variation in one subgenomic region of HIV-1 does not necessarily indicate a homogenous population of virus because different regions within the same virus genome can vary independently $(51,53$, $60,61)$. An alternative explanation is that homogeneity of virus sequences in an infant at 7 or $14 \mathrm{wk}$ of age could reflect selective outgrowth of one of several maternal variants that were transmitted.

HIV-1 genotypes not found in paired samples from a mother and one newborn close to the time of birth were detected subsequently, when all samples from the mother and her infant were analyzed. A representative profile of which maternal virus variants are actually transmitted may not be immediately evident, in part because of technical factors, such as the amount of target DNA amplified or the number of sequences analyzed in a sample set. In addition, biological factors undoubtedly contribute to the profile of variants detected because of fluctuations in frequencies of HIV-1 genotypes in peripheral blood cells (61-64). Particular HIV-1 variants can be sequestered in other tissues, such as the lymph nodes, before emerging in PBMCs $(65,66)$. Compartmentalization of the virus or activation of virus expression would explain the appearance of additional maternal HIV-1 genotypes in infants weeks after birth.

Timing of vertical transmission, that is, whether the infants were infected early in gestation or near birth, cannot be determined from our studies primarily because of the persistence of maternal HIV-1 genetic variants, in some cases, throughout pregnancy. Nonetheless, studies of genetic variation in HIV-1 do provide insights into mechanisms of transmission. Because multiple maternal viruses were identified in the infants, our studies indicate that vertical HIV-1 infection is not always limited to selective transmission of a single virion or a single virus genotype. Vertical transmission could occur by cell-free virus in maternal blood if the various maternal HIV-1 genotypes were expressed (43). Mother-to-infant transmission of HIV-1 may involve cell-associated virus, as well (11). In our studies, multiple HIV-1 variants detected in infants were closely related to many of the virus variants in maternal peripheral blood cells. The extent of variation in HIV-1 genotypes that can be detected in maternal cells in small volumes of peripheral blood would be sufficient to account for transmission of cell-associated virus. Maternal lymphocytes have been identified in the blood of newborns, for example, in infants with severe combined immunodeficiency disease (67). The extent to which small numbers of maternal cells could be present in infants infected by vertical transmission of HIV-1 remains to be examined.

Genetically related viruses persisted for a number of years within members of each family. An unexpected result was the distinct pattern of amino acid signature residues that was conserved in V1 and V2 sequences among populations of viruses in each family. Persistence of the signature pattern independent of the overall extent of genetic variation in V1 and V2 contributed to an unambiguous fingerprint that linked epidemiologically related viruses for almost $4 \mathrm{yr}$ after transmission. Results of our studies indicate that the V1 and V2 domains can be important for evaluation of the molecular epidemiology of HIV-1 transmission when the transmission link is in question.

\section{Acknowledgments}

The authors are grateful for helpful comments and discussion from Livia Pedroza Martins, Nelson Michael, William Farmerie, and Wayne Potts.

This research was funded in part by the National Institutes of Health under the auspices of the National Institute of Allergy and Infectious Diseases grant R01 28210, and by the Pediatric AIDS Foundation grants 500028-7-PG and 500108-9-PGR.

\section{References}

1. Scott, G. B., M. A. Fischl, N. Klimas, M. A. Fletcher, G. M. Dickinson, R. S. Levine, and W. P. Parks. 1985. Mothers of infants with the acquired immunodeficiency syndrome: evidence for both symptomatic and asymptomatic carriers. J. Am. Med. Assoc. 253:363-366.

2. Cowan, M. J., D. Hellman, D. Chudwin, D. W. Wara, R. S. Chang, and A. J. Ammann. 1984. Maternal transmission of acquired immune deficiency syndrome. Pediatrics. 73:382-386.

3. Kind, C., B. Brandle, C.-A. Wyler, A. Calame, C. Rudin, U. B. Schaad, J. Schupbach, H.-P. Senn, L. Perrin, L. Matter, and the Swiss Neonatal HIV Study Group. 1992. Epidemiology of vertically transmitted HIV-1 infection in Switzerland: results of a nationwide prospective study. Eur. J. Pediatr. 151:442-448.

4. Italian Multicenter Study. 1988. Epidemiology, clinical features, and prognostic factors of pediatric HIV infection. Lancet. 2:1043-1045.

5. European Collaborative Study. 1988. Mother-to-child transmission of HIV infection. Lancet. 2:1039-1042.

6. Ryder, R. W., W. Nsa, S. E. Hassig, F. Behets, M. Rayfield, B. Ekungola, A. M. Nelson, U. Mulenda, H. Francis, K. Mwandagalirwa, et al. 1989. Perinatal transmission of the human immunodeficiency virus type 1 to infants of seropositive women in Zaire. N. Engl. J. Med. 320:1637-1642.

7. Blanche, S., C. Rouzioux, M.-L. G. Moscato, F. Veber, M.-J. Mayaux, C. Jacomet, J. Tricoire, A. Deville, M. Vial, G. Firtion, et al. and the HIV Infection in Newborns French Collaborative Study Group. 1989. A prospective study of infants born to women seropositive for human immunodeficiency virus type 1 . N. Engl. J. Med. 320:1643-1648.

8. Andiman, W. A., J. Simpson, and B. Olson. 1990. Rate of transmission of HIV type 1 infection from mother to child and short-term outcome of neonatal infection. Am. J. Dis. Child. 144:758-766.

9. European Collaborative Study. 1991. Children born to women with HIV-1 infection: natural history and risk of transmission. Lancet. 337:253-260.

10. Caldwell, M. B., and M. F. Rogers. 1991. Epidemiology of pediatric HIV infection. Ped. Clin. North Am. 38:1-16.

11. Report of a Consensus Workshop. 1992. Maternal factors involved in mother-to-child transmission of HIV-1. J. Acquired Immune Defic. Syndr. 5:1019-1029.

12. Broliden, P. A., V. Moschese, K. Ljunggren, J. Rosen, C. Fundaro, A. Plebani, M. Jondal, P. Rossi, and B. Wahren. 1989. Diagnostic implications of specific immunoglobulin $\mathrm{G}$ patterns of children born to HIV-infected mothers. AIDS (Phila.). 3:577-582. 
13. Goedert, J., H. Mendez, J. E. Drummond, M. Robert-Guroff, H. L. Minkoff, S. Holman, R. Stevens, A. Rubinstein, W. A. Blattner, A. Willoughby, and S. H. Landesman. 1989. Mother-to-infant transmission of human immunodeficiency virus type 1: association with prematurity or low anti-gp120. Lancet. 2:1351-1354.

14. Rossi, P., V. Moschese, P. A. Broliden, C. Fundaro, I. Quinti, A. Plebani, C. Giaquinto, P. Tovo, K. Ljunggren, and J. Rosen. 1989. Presence of maternal antibodies to human immunodeficiency virus-1 envelope glycoprotein gp120 epitopes correlates with the uninfected status of children born to seropositive mothers. Proc. Natl. Acad. Sci. USA. 86:8055-8056.

15. Devash, Y., T. Cavelli, D. Wood, K. Reagan, and A. Rubenstein. 1990. Vertical transmission of human immunodeficiency virus is correlated with the absence of high-affinity/avidity maternal antibodies to the gp 120 principal neutralizing domain. Proc. Natl. Acad. Sci. USA. 87:3445-3449.

16. Rossi, P., V. Moschese, A. de Rossi, B. Wahren, M. Jansson, V. Lombardi, and H. Wigzell. 1991. Maternal antibody epitope mapping in mother-to-child transmission of HIV. Immunobiol. Proteins Pept. 6:47-52.

17. Ljunggren, K., V. Moschese, and P. Broliden. 1990. Antibodies mediating cellular cytotoxicity and neutralization correlate with a better clinical stage in children born to human immunodeficiency virus infected mothers. J. Infect. Dis. 161:198-202.

18. Parkeh, B., N. Shaffer, C. Pau, E. Abrams, P. Thomas, H. Pollack, M. Bamji, A. Kaul, G. Schochetman, M. Rogers, J. R. George, and The NYC Perinatal HIV Transmission Collaborative Group. 1991. Lack of correlation between maternal antibodies to $\mathrm{V} 3$ loop peptides of $\mathrm{gp} 120$ and perinatal transmission. AIDS (Phila.). 5:1179-1184

19. Kollman, T. R., A. Rubinstein, W. D. Lyman, R. Soiero, and H. Goldstein. 1991. Characterization of IgG and IgG subclass antibodies present in paired maternal and fetal serum which are directed against HIV-1 proteins. AIDS Res. Hum. Retroviruses. 7:847-854.

20. Ugen, K. E., J. J. Goedert, J. Boyer, Y. Refaeli, I. Frank, W. V. Williams, A. Willoughby, S. Landesman, A. Rubinstein, J. Berzofsky, T. Kieber-Emmons, and D. B. Weiner. 1992. Vertical transmission of HIV infection: maternal humoral immune responses to gp 120 and gp41 peptides. J. Clin. Invest. 89:183189.

21. Goudsmit, J., K. Nicole, T. Back, and P. L. Nara. 1991. Genomic diversity and antigenic variation of HIV-1: links between pathogenesis, epidemiology and vaccine development. FASEB (Fed. Am. Soc. Exp. Biol.). J. 5:2427-2436.

22. Fenyo, E. M., L. Morfeldt-Manson, F. Chiodi, B. Lind, A. von Gegerfelt, J. Albert, E. Olausson, and B. Asjo. 1988. Distinct replicative and cytopathic characteristics of human immunodeficiency virus isolates. J. Virol. 62:44144419.

23. De Jong, J.-J., J. Goudsmit, W. Keulen, B. Klaver, W. Krone, M. Tersmette, and A. De Ronde. 1992. Human immunodeficiency virus type 1 clones chimeric for the envelope V3 domain differ in syncytium formation and replication capacity. J. Virol. 66:757-765.

24. Schuitemaker, H., M. Koot, N. A. Kootstra, M. W. Dercksen, R. E. Y. de Goede, R. P. van Steenwijk, J. M. A. Lange, J. K. M. Eeftink Schattekerk, F. Miedema, and M. Tersmette. 1992. Biological phenotype of human immunodeficiency virus type 1 clones at different stages of infection: progression of disease is associated with a shift from moncytotropic to T-cell-tropic virus populations. $J$. Virol. 66:1354-1360.

25. De Rossi, A., M. Pasti, F. Mammano, L. Ometto, C. Giaquinto, and L. Chieco-Bianchi. 1991. Perinatal infection by human immunodeficiency virus type 1 (HIV-1): relationship between proviral copy number in vivo, viral properties in vitro, and clinical outcome. J. Med. Virol. 35:283-289.

26. Modrow, S., B. H. Hahn, G. M. Shaw, R. C. Gallo, F. Wong-Staal, and H. de Wolf. 1987. Computer-assisted analysis of envelope protein sequences of seven human immunodeficiency virus isolates: predictions of antigenic epitopes in conserved and variable regions. J. Virol. 61:570-578.

27. Myers, G. M., B. Korber, J. A. Berzofsky, R. F. Smith, and G. N. Pavlakis. 1992. Human Retroviruses and AIDS. Los Alamos National Laboratory, Los Alamos, NM. $1050 \mathrm{pp}$.

28. van Tijn, D., C. A. B. Boucher, M. Bakker, and J. Goudsmit. 1989. Antigenicity of linear B-cell epitopes in the C1, V1, and V3 region of HIV-1 gp 120. J. Acquired Immune Defic. Syndr. 2:303-306.

29. LaRosa, G. J., J. P. Davide, K. Weinhold, J. A. Waterbury, A. T. Profy, J. A. Lewis, A. J. Langlois, G. R. Dreesman, R. N. Boswell, P. Shadduck, et al. 1990. Conserved sequence and structural elements in the HIV-1 principal neutralizing determinant. Science (Wash. DC). 249:932-935.

30. Shioda, T., J. Levy, and C. Cheng-Mayer. 1991. Macrophage and T cellline tropisms of HIV-1 are determined by specific regions of the envelope gp 120 gene. Nature (Lond.). 349:167-169.

31. Nara, P. L., R. Garrity, A. Minassian, and J. Goudsmit. 1991. Envelope plasticity outside the V3 and gp 120-CD4 binding epitopes results in resistance to neutralization and fusion without loss of antibody binding: implications to HIV 1 vaccine design. FASEB (Fed. Am. Soc. Exp. Biol.). J. 5:175-181.

32. Westervelt, P., D. P. Trowbridge, L. G. Epstein, B. M. Blumber, Y. Li, B. H. Hahn, G. M. Shaw, R. W. Price, and L. Ratner. 1992. Macrophage tropic determinants of human immunodeficiency virus type 1. J. Virol. 66:2577-2582.
33. Sharpless, N. E., W. A. O'Brien, E. Verdin, C. V. Kufta, S. Irvin, Y. Chen, and M. Dubois-Dalco. 1992. Human immunodeficiency virus type 1 tropism for brain microglial cells is determined by a region of the env glycoprotein that also controls macrophage tropism. J. Virol. 66:2588-2593.

34. Fung, M. S. C., C. Sun, W. L. Gordon, R.-S. Liou, T. W. Chang, W. Sun, E. S. Daar, and D. D. Ho. 1992. Identification and characterization of a neutralization site within the second variable region of human immunodeficiency virus type $1 \mathrm{gp} 120$. J. Virol. 66:848-856.

35. Sullivan, N., M. Thalix, C. Furman, D. D. Ho, and J. Sodroski. 1993. Effect of the amino and changes in the $\mathrm{V} 1 / \mathrm{V} 2$ region of the human immunodeficiency virus type $1 \mathrm{gp} 120$ glycoprotein on subunit association, syncytium formation, and recognition by a neutralizing antibody. J. Virol. 67:3674-3679.

36. Groenink, M., R. A. M. Fouchier, S. Broersen, C. H. Baker, M. Koot, A. B. van't Wout, H. G. Huisman, F. Miedema, M. Tersmette, and H. Schuitemaker. 1993. Relation of phenotype evolution of HIV-1 to envelope V2 configuration. Science (Wash. DC). 260:1513-1516.

37. Goodenow, M., T. Huet, W. Saurin, S. Kwok, J. Sninsky, and S. WainHobson. 1989. HIV-1 isolates are rapidly evolving quasispecies: evidence for viral mixtures and preferred nucleotide substitutions. J. Acquired Immune Defic. Syndr. 2:344-352.

38. Simmonds, P., L. Q. Zhang, F. McOmish, P. Balfe, C. A. Ludlam, and A. J. Leigh Brown. 1991. Discontinuous sequence change of human immunodeficiency virus (HIV) type 1 env sequences in plasma viral and lymphocyte-associated proviral populations in vivo: implications for models of HIV pathogenesis. J. Virol. 65:6266-6276.

39. Wolfs, T. F. W., J.-J de Jong, H. vanden Berg, J. M. G. H. Tijnagel, W. J. A. Krone, and J. Goudsmit. 1990. Evolution of sequences encoding the principal neutralization epitope of human immunodeficiency virus 1 is host dependent, rapid, and continuous. Proc. Natl. Acad. Sci. USA. 87:9938-9942.

40. Burger, H., B. Weiser, K. Flaherty, J. Gulla, P.-N Nguyen, and R. Gibbs. 1991. Evolution of human immunodeficiency virus type 1 nucleotide sequence diversity among close contacts. Proc. Natl. Acad. Sci. USA. 88:11236-11240.

41. Ou, C.-Y., C. A. Ciesielski, G. Myers, C. I. Bandea, C-C. Luo, B. T. M Korber, J. I. Mullins, G. Schochetman, R. L. Berkelman, A. N. Economous, et al. and the Laboratory Investigative Group, Epidemiologic Investigation Group. 1992. Molecular epidemiology of HIV transmission in a dental practice. Science (Wash. DC). 256:1165-1171.

42. Wolinsky, S., C. M. Wike, B. T. M. Korber, C. Hutto, W. P. Parks, L. L. Rosenblum, K. J. Kunstman, M. R. Furtado, and J. L. Munoz. 1992. Selective transmission of human immunodeficiency virus type 1 variants from mothers to infants. Science (Wash. DC). 255:1134-1137.

43. Scarlatti, G., T. Leitner, E. Halap, J. Wahlberg, P. Marchisio, M. A. Clericii-Schoeller, H. Wigzel, E. M. Fenyo, J. Albert, M. Uhlen, and P. Rossi. 1993. Comparison of variable region 3 sequences of human immunodeficiency virus type 1 from infected children with the RNA and DNA of the virus populations of their mothers. Proc. Natl. Acad. Sci. USA. 90:1721-1725.

44. Center for Disease Control. 1987. Classification system for human immunodeficiency virus (HIV) infection in children under 13 years of age. Morb. Mortal. Wkly Rep. 36:833-845.

45. Sambrook, J., E. F. Fritsch, and T. Maniatis. 1989. Molecular Cloning: $A$ Laboratory Manual. Cold Spring Harbor Laboratory, Cold Spring Harbor, NY.

46. Leonard, C. K., M. W. Spellman, L. Riddle, R. J. Harris, J. N. Thomas, and T. J. Gregory. 1990. Assignment of intrachain disulfide bonds and characterization of potential glycosylation sites of the type 1 recombinant human immunodeficiency virus envelope glycoprotein (gp/20) expressed in Chinese hamster ovary cells. J. Biol. Chem. 265:10373-10382.

47. Nei, M., and L. Jin. 1989. Variances of the average numbers of nucleotide substitutions within and between populations. Mol. Biol. Evol. 6:290-300.

48. She, J. X., S. Boehme, T. W. Wang, F. Bonhomme, and E. K. Wakeland. 1991. Amplification of major histocompatibility complex class II gene diversity by intra-exonic recombination. Proc. Natl. Acad. Sci. USA. 88:453-457.

49. Goedert, J. J., A.-M. Duliege, C. I. Amos, S. Felton, R. J. Biggar, and The International Registry of HIV-exposed Twins. 1991. High risk of HIV-1 infection for first-born twins. Lancet. 338:1471-1475.

50. Scott, G. B., C. Hutto, R. W. Makuch, M. T. Mastrucci, T. O'Connor, C. D. Mitchell, E. J. Trapido, and W. P. Parks. 1988. Survival in children with perinatally acquired human immunodeficiency virus type 1 infection. $N$. Engl. $J$. Med. 321:1791-1796.

51. Holmes, E. C., L. Q. Zhang, P. Simmonds, C. A. Ludlam, and A. J. Leigh-Brown. 1992. Convergent and divergent sequence evolution in the surface envelope glycoprotein of human immunodeficiency virus type 1 within a single infected patient. Proc. Natl. Acad. Sci. USA. 89:4835-8439.

52. Lamers, S. L., J. W. Sleasman, J. X. She, K. A. Barrie, S. M. Pomeroy, D. J. Barrett, and M. M. Goodenow. 1993. Independent variation and positive selection in $e n v \mathrm{~V} 1$ and V2 domains within maternal-infant strains of human immunodeficiency virus type 1 in vivo. J. Virol. 67:3951-3960.

53. Kusumi, K., B. Conway, S. Cunningham, A. Berson, C. Evans, A. K. N. Iversen, D. Colvin, M. V. Gallo, S. Coutre, E. G. Shpaer, et al. 1992. Human immunodeficiency virus type 1 envelope gene structure and diversity in vivo and after cocultivation in vitro. $J$. Virol. 66:875-885. 
54. Pedroza Martins, L., N. Chenciner, and S. Wain-Hobson. 1992. Complex intrapatient sequence variation in the $\mathrm{V} 1$ and $\mathrm{V} 2$ hypervariable regions of the HIV-1 gp120 envelope sequence. Virology. 191:837-845.

55. Michael, N. L., G. Chang, P. K. Ehrenberg, M. T. Vahey, and R. R. Redfield. 1993. HIV-1 proviral genotypes from the peripheral blood mononuclear cells of an infected patient are differentially represented in expressed sequences. J. Acquired Immune Defic. Syndr. 6:1073-1085.

56. Cichutek, K., H. Merget, S. Norley, R. Linde, W. Kreuz, M. Gahr, and R. Kurth. 1992. Development of a quasispecies of human immunodeficiency virus type 1 in vivo. Proc. Natl. Acad. Sci. USA. 89:7365-7369.

57. Saag, M. S., M. J. Crain, W. D. Decker, S. Campbell-Hill, S. Robinson, W. E. Brown, M. Leuther, R. J. Whitley, B. H. Hahan, and G. M. Shaw. 1991. High-level viremia in adults and children infected with human immunodeficiency virus: relation to disease and $\mathrm{CD}^{+}$lymphocyte levels. J. Infect. Dis. 164:72-80.

58. Piatak, M., M. S. Saag, L. C. Yang, S. J. Clark, J. C. Kappes, K.-C. Luk, B. H. Hahn, G. M. Shaw, and J. D. Lifson. 1993. High levels of HIV-1 in plasma during all stages of infection determined by competitive PCR. Science (Wash. DC). 259:1749-1754.

59. Pang, S., Y. Shlesinger, E. S. Daar, T. Moudgil, D. D. Ho, and I. S. Y. Chen. 1992. Rapid generation of sequence variation during primary HIV-1 infection. $A I D S$. 6:453-460.

60. Delassus, S., R. Cheynier, and S. Wain-Hobson. 1991. Evolution of human immunodeficiency virus type $1 n$ ef and long terminal repeat sequences over 4 years in vivo and in vitro. J. Virol. 65:225-231.

61. Pedroza Martins, L., N. Chenciner, B. Asjo, A. Meyerhans, and S. Wain-
Hobson. 1991. Independent fluctuations of HIV-1 rev and gp4l quasispecies in vivo. J. Virol. 65:4502-4507.

62. Meyerhans, A., R. Cheynier, J. Albert, M. Seth, S. Kwok, J. Sninsky, L. Morfeldt-Manson, B. Ajso, and S. Wain-Hobson. 1989. Temporal fluctuations in HIV quasispecies in vivo are not reflected by sequential HIV isolations. Cell. 58:901-910.

63. Simmonds, P., L. Q. Zhang, F. McOmish, P. Balfe, C. A. Ludlam, and A. J. Leigh Brown. 1991. Discontinuous sequence changes of human immunodeficiency virus (HIV) type 1 env sequences in plasma viral and lymphocyte-associated proviral populations in vivo: implications for models of HIV pathogenesis. J. Virol. 65:6266-6276.

64. Delassus, S., R. Cheynier, and S. Wain-Hobson. 1992. Inhomogeneous distribution of human immunodeficiency virus (HIV) type 1 genomes within an infected spleen. J. Virol. 66:5642-5645.

65. Pantaleo, G., C. Graziosi, J. F. Demarest, L. Butini, M. Montroni, C. H. Fox, J. M. Orenstein, D. P. Kolter, and A. S. Fauci. 1993. HIV infection is active and progressive in lymphoid tissue during the clinically latent stage of disease. Nature (Lond.). 362:355-358.

66. Embretson, J., M. Zupanicic, J. L. Ribas, A. Burke, P. Racz, K. TennerRacz, and A. T. Haase. 1993. Massive covert infection of helper T lymphocytes and macrophages by HIV during the incubation period of AIDS. Nature (Lond.). 362:359-362.

67. Pollack, M. S., M. D. Kirkpatrick, N. Kapoor, B. Dupont, and R. J. O'Reilly. 1982. Identification by HLA typing of intrauterine-derived maternal T cells in four patients with severe combined immunodeficiency. $N$. Engl. J. Med. 307:662-666. 